\title{
Morpho-Syntactic Deficit in Children with Cochlear Implant: Consequence of Hearing Loss or Concomitant Impairment to the Language System?
}

\author{
Erika Benassi ${ }^{1, * \mathbb{C}}$, Sonia Boria ${ }^{2}$, Maria Teresa Berghenti ${ }^{3}$, Michela Camia $^{1}$, Maristella Scorza ${ }^{1}$ \\ and Giuseppe Cossu ${ }^{4}$
}

check for

updates

Citation: Benassi, E.; Boria, S.; Berghenti, M.T.; Camia, M.; Scorza, M.; Cossu, G. Morpho-Syntactic Deficit in Children with Cochlear Implant: Consequence of Hearing Loss or Concomitant Impairment to the Language System? Int. J. Environ. Res. Public Health 2021, 18, 9475. https://doi.org/10.3390/ ijerph18189475

Academic Editor: Stefan Nilsson

Received: 10 July 2021

Accepted: 6 September 2021

Published: 8 September 2021

Publisher's Note: MDPI stays neutral with regard to jurisdictional claims in published maps and institutional affiliations.

Copyright: (c) 2021 by the authors. Licensee MDPI, Basel, Switzerland. This article is an open access article distributed under the terms and conditions of the Creative Commons Attribution (CC BY) license (https:// creativecommons.org/licenses/by/ $4.0 /)$
1 Department of Biomedical, Metabolic and Neural Sciences, University of Modena and Reggio Emilia, 42122 Reggio Emilia, Italy; michela.camia@unimore.it (M.C.); maristella.scorza@unimore.it (M.S.)

2 Center for the Diagnosis, Treatment and Study of Communication and Socialization Disorders, NPIA, AUSL of Parma, 43125 Parma, Italy; soboria@ausl.pr.it

3 Department of Medicine and Surgery, University of Parma, 43126 Parma, Italy; mariateresa.berghenti@unipr.it

4 Medical Centre of Phoniatrics, 35142 Padova, Italy; gcossu@centrofoniatria.it

* Correspondence: erika.benassi@unimore.it

\begin{abstract}
Background: Among implanted children with similar duration of auditory deprivation and clinical history, the morpho-syntactic skills remain highly variable, suggesting that other fundamental factors may determine the linguistic outcomes of these children, beyond their auditory recovery. The present study analyzed the morpho-syntactic discrepancies among three children with cochlear implant (CI), with the aim of understanding if morpho-syntactic deficits may be characterized as a domain-specific language disorder. Method: The three children (mean age $=7.2 ; \mathrm{SD}=0.4$ ) received their CI at 2.7, 3.7, and 5.9 years of age. Their morpho-syntactic skills were evaluated in both comprehension and production and compared with 15 age-matched normal-hearing children (mean age $=6.6 ; \mathrm{SD}=0.3$ ). Results: Cases 1 and 2 displayed a marked impairment across morphology and syntax, whereas Case 3, the late-implanted child, showed a morpho-syntactic profile well within the normal boundaries. A qualitative analysis showed, in Cases 1 and 2, language deficits similar to those of normal hearing children with Developmental Language Disorder (DLD). Conclusions: We suggest that a severe grammatical deficit may be, in some implanted children, the final outcome of a concomitant impairment to the language system. Clinical implications for assessment and intervention are discussed.
\end{abstract}

Keywords: children with hearing loss; cochlear implant; morpho-syntactic impairment; language disorder

\section{Introduction}

In industrialized countries, the vast majority of children with neurosensorial severe to profound deafness can receive one or two cochlear implants (CIs) that can allow them to be exposed to spoken language in natural contexts, offering the opportunity for incidental language learning [1]. The age of implantation is credited to play a crucial role in the language acquisition of the implanted deaf children; intuitively, by making CI available at an early age, one would expect the gap between language development and chronological age to be minimized. A study by Svirsky [2], where 70 children were assessed 4 months before they received their CI and then again at 6,12,18,24, and 30 months after implantation, documented that an earlier CI led to better language proficiency. A study on Italian preschool children [3] revealed a highly significant effect of age at CI surgery on productive vocabulary, mean length of utterance (MLU), and sentence complexity, with preschool females implanted under 1 year showing better performance. While only partial, the restoration of hearing seems to reduce the risk of the child's missing critical periods of neural development, allowing for a relatively typical maturation of the auditory system [4]. 
Thus, some authors [5] suggested that implanting a CI in profoundly deaf children at the youngest age provided an optimal opportunity to acquire communication skills that approximated those of their peers with normal hearing. However, despite the $\mathrm{CI}$ expanding the possibilities for acoustic recovery in deaf children, improvements in language skills of these children are not always in line with what is expected [1]. Several studies conducted on large populations of implanted children have documented a relevant interindividual variability [1,2,6]. As Svirsky and colleagues [2] pointed out, some children's language abilities remain severely delayed even after more than 2 years of experience with their cochlear implant. A study conducted on 181 children who received a cochlear implant by age 5 indicated that some $40 \%$ of the sample failed to acquire a linguistic proficiency comparable with that of typically developing (TD) children [6]. Nikolopoulos and colleagues [7] indicated that, although language acquisition was faster and more efficient in those children who received a CI before age 4, their acquisition of spoken grammar was considerably delayed. Lund [8] showed that the magnitude of difference in language abilities between children with CI and normally hearing children did not appear related to age of implantation or to duration of implantation, and other studies still found significant differences between children with CI and TD children in many linguistic skills (e.g., semantics, syntax, spoken language, pragmatics) with lower performance in the implanted children $[9,10]$. For instance, Rinaldi and colleagues [9] selected deaf toddlers that received their $\mathrm{CI}$ within the second year of life, experienced binaural stimulation, were not exposed to sign language, had no additional disability, and had parents actively involved in their child rehabilitation; however, despite this careful selection of the sample, they found linguistic skills within normal limits in fewer than half of the children. The study conducted by Wie [11] in children that received bilateral CIs between 5 and 18 months of age found that, after $12-48$ months with CI, only $57 \%$ of them had expressive language skills within the normative range.

These conflicting effects of the $\mathrm{CI}$ on verbal language development have created a significant debate in scientific world, with some researchers claiming that a very early implantation associated to early oral therapy (without exposure to signs) may promote good language performance in children with CI (e.g., [12,13]), whereas other argue that $\mathrm{CI}$ and oral therapy alone may not be sufficient to ensure typical language development (e.g., $[1,8,14])$. In support of this latter view, there is now evidence that environmental factors (e.g., linguistic input, communication modalities used during interactions, and exposure to a sign language) explain a considerably larger proportion of the variance in receptive and productive language than age at implantation (e.g., [15-17]). For example, research has provided initial support to the hypothesis that deaf children with CI can develop better spoken language skills when exposed to a sign language [15,16], demonstrating that early exposure to sign language in a bilingual environment allows the child with CI to express ideas and concepts that they were not yet able to vocalize, thus promoting the development of the language system [16]. Furthermore, domain-general neurocognitive processes, such as sequential processing, working memory, and executive functions, may support the language development of these children or, on the contrary, hinder it when impaired (e.g., [18-20]).

It is clear that understanding variability in $\mathrm{CI}$ outcomes requires a broader perspective that goes beyond hearing alone [1]. Moreover, it is undeniable that, while generally effective in transducing sounds into electrical signals for the brain, CIs remain artificial devices that can only approximate the natural hearing experience. Certainly, the lack of full access to a complete language (verbal and sign language) during the critical perceptual window $[21,22]$ may negatively impact the neurological development of the language areas [22]. Thus, CIs do not necessary protect the child from failures in full language acquisition [14].

As reported in a review by Caselli and colleagues [23], difficulties in comprehension are often greater than difficulties in production, and difficulties in morphosyntactic aspects are greater than those in lexical aspects. Most of the studies that focused on these linguistic 
abilities investigated English-speaking children with CI. The differences between the English and Italian languages highlight the importance to focus on studies that investigated morpho-syntactic skills in Italian children with CI [24]. Italian has specific linguistic characteristics, with a richer morphology compared to English. In fact, both bound and free morphology (i.e., inflections of nouns and adjectives, verb conjugation, and articles, pronouns, and prepositions) are quite complex [25]. Previous studies [10,26] found that Italian children with CI made more morphological and syntactic errors in their production task, compared with their normal hearing peers, with difficulties in free morphology (such as articles, pronouns, and clitics) in particular. In a recent study, Giustolisi and colleagues [27] investigated the production of third-person singular accusative object clitics (3DO clitics) in 14 Italian-speaking children who received a CI between age 1 and 4. The majority of participants had good language performance; however, some children showed severe difficulties in 3DO clitics tasks. These difficulties could be due to perceptual problems that continue to be present despite the CI [25] and may be influenced by the duration of hearing exposure [26]. However, according to other authors [27-29], it is also possible that the language difficulties in some of these children may represent a manifestation of more extensive morpho-syntactic and linguistic impairments.

Hawker and colleagues [29] described six prelingually deaf children with disproportionate morpho-syntactic problems, in both production and comprehension, when they were matched to six other implanted children for etiology, age at implantation, and hearing experience with $\mathrm{CI}$. The authors argued that it is important to consider alternative explanations that locate the source of the problem in the brain, i.e., in the CI or the auditory periphery. It is known that around $4 \%$ to $6 \%$ of children who are normally hearing have DLD, a condition for which there is a strong genetic predisposition. As reported by Hawker and colleagues [29], "because there is no reason to suppose that deafness protects against DLD, we can anticipate that a similar proportion of children who are deaf will have a genetic predisposition to language impairments [ ... ] If a child had the same risk factors and a hearing loss, it seems plausible that this would dramatically impair language acquisition". In other words, in certain circumstances, the linguistic brain of some implanted children may not be fully equipped for the computation of language and for those children the acquisition of language may follow profoundly divergent patterns [28].

This line of reasoning leads to speculate that some congenitally deaf children may suffer from a concomitant linguistic impairment, which can be further amplified by the sensory loss. The co-occurrence of deafness and linguistic impairment might, to some extent, explain a proportion of the variance in language acquisition among deaf children with $\mathrm{CI}$ and their atypical linguistic patterns.

\section{The Current Study}

The current study analyzed the morpho-syntactic discrepancies, in both comprehension and production, among three highly intelligent prelingually deaf children with CI; particular attention was devoted to the production of narrative skills. As the main research question, we wondered if the reported delay in language acquisition among implanted children may be characterized as a domain-specific language disorder. As reported above, children who receive a CI display a large variability in linguistic proficiency, and it is important to remain aware that early implantation does not necessarily ensure that the development of language skills will also fully occur [1]. In the present study, we hypothesized that the morpho-syntactic difficulties of two of three children with CI were not only a consequence of the lack of exposure to a natural and optimal hearing during the critical perceptual window but also indicators of a concomitant impairment to the language system. Specifically, we expected that these two children showed clinical markers similar to those of Italian children with DLD, such as short and few complex sentences, omissions of content and function words, many substitutions of free and bound morphemes, and atypical errors in nominal, adjectival, and verbal inflection [30,31]. 
To this aim, we suggest that detailed single case studies might positively complement the research conducted on large samples of deaf children. The single-case perspective does indeed provide an ideal observatory for a finer-grained analysis of divergent trajectories in deaf children with $\mathrm{CI}$.

\section{Materials and Methods}

\subsection{Participants}

Three children (mean age $=7.2 ; \mathrm{SD}=0.4$ ), all females, affected by congenital bilateral profound sensorineural hearing loss (SNHL), participated in this study. We chose these three children because, as described in more detail below, they showed similar clinical, family, and school history, they were operated by the same surgeon and with the same type of CI, they received oral speech therapy by the same speech therapist, they reached the same postimplant auditory threshold, and they had the same nonverbal intelligence level.

All of them were followed at the Otolaryngology and Otoneurosurgery Unit of the University of Parma. All cases fulfilled the following criteria: (1) SNHL identified with universal newborn hearing screening program; (2) no evidence of inner ear malformations at high-resolution CT scan and MRI evaluation; (3) no significant visual, motor, or cognitive problems that might interfere with speech and language development; (4) inclusion in an auditory-verbal (AVT) rehabilitation program; (5) normal-hearing parents and Italian as the native language.

In Case 1, genetic inquiry was negative for mutation of gene Cx 26; in Case 2, genetic inquiry revealed that both child's parents are healthy bearers of a mutation of the connexin 26 gene (Cx26), thus indicating that her deafness has an inherited cause; in Case 3, genetic inquiry revealed a deletion in Cx 26.

Details concerning age at first amplification, at intervention enrolment, and at CI surgery are presented in Table 1 . The click-evoked auditory brainstem response (ABR) was absent at $90 \mathrm{~dB}$ nHL in all cases. Unaided preimplant auditory threshold level was $\leq 90 \mathrm{~dB}$ (PTA) for each one of the three deaf children, whereas the aided hearing threshold level was between 50 and $60 \mathrm{~dB}$. From the diagnosis, each child regularly followed a rehabilitation program with a speech therapist.

Table 1. Clinical data and nonverbal scores from CPMs (Colored Progressive Matrices) for each of the three deaf children and the control group.

\begin{tabular}{|c|c|c|c|c|}
\hline & Case 1 & Case 2 & Case 3 & $\begin{array}{l}\text { TD Children } \\
\quad(n=15)\end{array}$ \\
\hline Chronological age & 6.7 years & 7.5 years & 7.5 years & $\mathrm{M}=6.6(\mathrm{SD}=0.3)$ \\
\hline Sex & female & female & female & $\begin{array}{c}7 \text { males }(47 \%) \text { and } 8 \text { females } \\
(53 \%)\end{array}$ \\
\hline $\begin{array}{l}\text { Hearing aids (age at first } \\
\text { amplification) }\end{array}$ & 19 months & 21 months & 13 months & 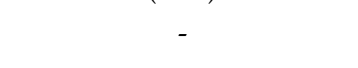 \\
\hline $\begin{array}{l}\text { Speech therapy (age } \\
\text { at initiation) }\end{array}$ & 20 months & 21 months & 14 months & - \\
\hline Type of speech therapy & oral & oral & oral & - \\
\hline Age at CI surgery & 2.7 years & 3.7 years & 5.9 years & - \\
\hline $\begin{array}{l}\text { CPM (raw score; } \\
\text { percentile value) }\end{array}$ & $32 ;>95$ th & $29 ;>95$ th & $30 ;>95$ th & $\mathrm{M}=21.1(\mathrm{SD}=2.70) ; 90$ th \\
\hline $\begin{array}{l}\text { Type of school } \\
\text { Grade of school }\end{array}$ & $\begin{array}{l}\text { Traditional school } \\
\text { education } \\
\text { grade I }\end{array}$ & $\begin{array}{c}\text { Traditional school } \\
\text { education } \\
\text { grade I }\end{array}$ & $\begin{array}{c}\text { Traditional school } \\
\text { education } \\
\text { grade I }\end{array}$ & $\begin{array}{c}\text { Traditional school education } \\
\text { grade I }\end{array}$ \\
\hline Maternal educational level & $\begin{array}{c}\text { High level (high-school } \\
\text { diploma) }\end{array}$ & $\begin{array}{c}\text { High level (high-school } \\
\text { diploma) }\end{array}$ & $\begin{array}{c}\text { Low level } \\
\text { (middle-school } \\
\text { graduation) }\end{array}$ & $\begin{array}{c}8 \text { high level (53\%), } 7 \text { low } \\
\text { level }(47 \%)\end{array}$ \\
\hline
\end{tabular}

Case 1 and Case 2 received a CI at 2.7 and 3.7 years of age, respectively, while Case 3 received hers at 5.9 years of age (see Table 1). Although the CI was proposed earlier to this latter family, family personal conditions and concerns about surgery and CI (frequent and understandable among these families) delayed the surgery. All children were implanted with a Nucleus multichannel device (Cochlear Ltd., Sydney, Australia). Postimplant auditory threshold improved markedly, and, about 36 weeks after implantation (and also 
at the time of our testing), all three children ranged between 25 and $35 \mathrm{~dB}$. Their speech discrimination threshold was assessed by means of the routine clinical Protocol for the Evaluation of Results in Rehabilitative Audiology (PCVRAR) [32]. The findings revealed a high level of accuracy for all of the three children; their scores fell in the highest efficiency category (category 6, i.e., auditory recognition of words in open-set condition), according to [33].

All three children had a high nonverbal intelligence level, as they obtained a score above the 95th percentile on the Raven Colored Progressive Matrices (CPMs) [34] (see Table 1). Table 1 also shows details concerning school and maternal level education for the three cases.

Fifteen age-matched normal-hearing children (mean age $=6.6 ; \mathrm{SD}=0.3$; seven males and eight females), served as a control group for the narrative language task. These TD children were recruited in a primary school of Reggio Emilia (Italy) that voluntarily participated in the study. Children were included if they met the following criteria: (a) they spoke Italian as their first language; (b) they did not have any indications of major cerebral damage, congenital malformations, or visual and hearing impairment; (c) they did not have intellectual disabilities; (d) they received adequate schooling (i.e., regular school attendance). Their cognitive level was within the normal range (for details, see Table 1).

\subsection{Procedure}

The three children with CI were evaluated by their speech therapist at the Otolaryngology and Otoneurosurgery Unit of the University of Parma where the children were followed. Specifically, the deaf girls were examined during the individual assessment conducted in the room in which they received the speech therapy. The Test of Grammatical Comprehension for Children (TCGB), tests for the phonological evaluation of infant speech (PFLI), and CPM tests were carried out in a quiet room and were presented according to test recommendations, in live voice and given orally, during two 45 min sessions.

The TD children were individually met in a quiet room of the school by a psychologist; after a familiarization phase with the examiner, the TCGB, PFLI, and CPM tests were administered during a 45 min session.

Since an Ethics Commission was not present in the University of Parma where and when the study was conducted, the study did not receive formal ethical approval. However, the study was conducted according to the guidelines of the Declaration of Helsinki and to ethical principles by APA and AIP (Italian Psychological Association), as well as in line with current Italian legislation.

The children and their parents were informed in detail about the aims of the study, the voluntary nature of their participation, and their right to withdraw from the study at any time. The children's parents gave informed written consent for participation in the study, data analysis, and data publication.

\subsection{Measures}

The Test of Grammatical Comprehension for Children (TCGB) [35] TCGB is an Italian test for assessing the comprehension of morphology and syntax. Normative scores are provided for an age range from 3.6 to 8 years of age. The TCGB comprises 76 sentences, aimed at assessing eight different grammatical structures (locative, flexional, active affirmative, active negative, passive affirmative, passive negative, relative sentences, and dative sentences) and a figured album. For each sentence produced by the examiner, the child is required to point to the correct picture among four alternatives. The normative scores are calculated as a function of the number of errors.

Tests for the phonological evaluation of infant speech (PFLI) [36]. PFLI was originally designed as a clinical tool for a qualitative and quantitative analysis of phonological disorder in preschool and school children with language impairment. In clinical practice, the PFLI is widely used for eliciting narrative language. The test comprises 90 brightly colored cartooned pictures of common daily-life actions and situations. For the purposes 
of our study, we selected 10 pictures (i.e., no. 5, 10, 13, 15, 24, 28, 29, 31, 39, and 48) and used them for prompting a story and thus for examining the morpho-syntactic skills in spontaneous narrative production. Two extra pictures were used for training. Each picture was presented one at a time and the child was required to look carefully and to tell a story about what is happening. No time limitations were set on the child for the description of the picture.

\subsection{Coding}

With regard to the children's narrative productions (from both the three deaf children and the control group), they were tape-recorded and then transcribed by two blinded examiners (first author and the speech therapist) for scoring and further inspection (see Appendix A). Free and bound morphology was the main target of our linguistic analysis from the children' elicited stories. We counted the number of occurrences of morphological structures and the number and quality of errors made by each child. We also calculated the MLU (mean length utterance) score for each child, in accordance with the currently agreed criteria [37]. We also considered that the boundaries of the utterance were determined by the occurrence of at least two of the following four criteria [30]: (1) mutual interaction in dialogue; (2) an interval of 300 to $500 \mathrm{~m} / \mathrm{s}$ of silence taken as a boundary for a sentence; (3) more than one topic from the picture described; (4) a falling prosody, to indicate the conclusion of a sentence. Within each accepted utterance, we counted all the words uttered by the child, including articles, particles, and conjunctions. However, when considering typical expressions, such as, for example, "once upon a time", the whole utterance was counted as a single word [38]. The variables for scoring the narrative language were quantified according to the following criteria:

Lexical diversity. It represented the number of words produced in the session. This measure reflected both the productivity and the diversity of each child's language.

Number of sentences. The candidate sentences were selected according to the presence of the following categories: noun phrases, verb phrases, and sentence complexity (when, for instance, a relative or subordinate clause was inserted).

Mean length utterance (MLU). Utterance length was defined as the mean number of words per utterance. An utterance was defined according to the above criteria.

Free morphemes. Free morphemes are meaningless particles that precede the nouns of the sentence. They include articles and particles and, in the Italian language, they specify gender and number in agreement with the noun they refer to.

Bound morphemes. Bound morphemes are word parts that modify the meaning of a root morpheme (e.g., the plural masculine " $i$ " in the word "bambini" [children], or the first-person plural of the present tense "amo" in the word "vediamo" [we see]).

Intercoder agreement between the two examiners was $90 \%$.

\subsection{Statistical Analysis}

All statistical analyses were carried out using SPSS 23.0 for Windows.

With regard to morpho-syntactic comprehension (TCGB), for each deaf child, we calculated raw scores and percentile values for each type of error and for total score, using conversion tables provided by the authors of TCGB [35].

Regarding morpho-syntactic production (PFLI), we conducted statistical comparisons between the three deaf children and TD children considering the following variables: lexical diversity, number of sentences, MLU, and morphological errors (on free and bound morphemes). For each participant and for each variable, we calculated $z$-scores (compared to control group), and the alpha was set at 0.05 .

\section{Results}

Results of the qualitative analysis of the deaf children performance in the TCGB are presented in Table 2. The results indicated that mastery of grammatical comprehension was unevenly distributed across the three deaf children; Case 1 and Case 2 displayed a marked 
impairment across morphology and syntax, whereas Case 3 showed a morpho-syntactic profile well within the normal boundaries. In particular, a qualitative analysis indicated that Case 1, similarly to Case 3, scored no errors in the section of locative sentences, whereas Case $2 \mathrm{had}$ an error score of 3.5. A similar picture emerged from testing relative sentences. However, when we moved to flexional morphology, the situation changed; Case 1 and Case 2 made a very high number of errors ( 4.5 and 3, respectively), while Case 3 made no error (see Table 2). These numbers, according to the normative data, correspond to $25 \%$ and $21 \%$ of correct responses for flexional morphology. By considering that, in this domain, the mean percentage of correct responses for their ages equates to $88 \%$ and $86 \%$, respectively, we obtained a precise measure of the grammatical distance between these two deaf children (Case 1 and Case 2) and their normal-hearing peers, no less than between them and the other deaf child. Furthermore, Case 2's language comprehension was by far the more severely impaired, since her responses were inaccurate across all the tested grammatical structures. Indeed, she also made many errors in the dative sentences, which are usually acquired at about $3-4$ years of age [31].

Table 2. Results (total error raw score, error raw scores for each type of sentence, and percentile values) for the TCGB in the three deaf children with CI.

\begin{tabular}{|c|c|c|c|c|c|c|}
\hline \multirow{2}{*}{$\begin{array}{c}\text { TCGB } \\
\text { Error Type }\end{array}$} & \multicolumn{2}{|c|}{ Case 1} & \multicolumn{2}{|c|}{ Case 2} & \multicolumn{2}{|c|}{ Case 3} \\
\hline & $\begin{array}{l}\text { Error Raw } \\
\text { Score }\end{array}$ & $\begin{array}{l}\text { Percentile } \\
\text { Value * }\end{array}$ & $\begin{array}{l}\text { Error Raw } \\
\text { Score }\end{array}$ & $\begin{array}{c}\text { Percentile } \\
\text { Value * }\end{array}$ & $\begin{array}{l}\text { Error Raw } \\
\text { Score }\end{array}$ & $\begin{array}{l}\text { Percentile } \\
\text { Value * }\end{array}$ \\
\hline Locative sentences & 0 & $>50$ th & 3.5 & $<10$ th & 0 & $>50$ th \\
\hline Flexional sentences & 4.5 & $<10$ th & 3 & $<10$ th & 0 & $>75$ th \\
\hline $\begin{array}{c}\text { Active affirmative } \\
\text { sentences }\end{array}$ & 0.5 & 10th & 1.5 & $<10$ th & 0 & $>50$ th \\
\hline Active negative sentences & 0.5 & 50 th & 3.5 & $<10$ th & 0 & $>50$ th \\
\hline $\begin{array}{c}\text { Passive affirmative } \\
\text { sentences }\end{array}$ & 1.5 & 10th & 3 & $<10$ th & 1 & 10th \\
\hline Passive negative sentences & 4.5 & $<10$ th & 3.5 & $<10$ th & 0.5 & 25 th \\
\hline Relative sentences & 0 & $>75$ th & 3 & $<10$ th & 0 & $>50$ th \\
\hline Dative sentences & 1 & 10th & 3.5 & $<10$ th & 0 & $>25$ th \\
\hline Total score & 12.5 & 10-25th & 24.5 & $<10$ th & 1.5 & 50 th \\
\hline
\end{tabular}

* Percentile values that demonstrate a deficit (defined as $\leq 10$ th) or a delay (defined as $\leq 25$ th) [35] are in bold.

The spontaneous language transcriptions are reported in Appendix A. The three implanted children showed a clearcut interindividual discrepancy in their morpho-syntactic production skills; grammatical accuracy and selection of the appropriate lexical items were, in fact, unevenly represented. To provide an example, when presented picture no. 5 of the PFLI (see Appendix A), Case 1 said "To see the mouse", and Case 2 said "The child watches the mouse ... the cheese ... the mouse eat [first person singular verb form] ... cat eats the... the [singular feminine article] cheese [masculine noun]". Case 3's description of the same picture, on the contrary, was the following: "There was a child, whose name was Luca. He put a cheese on the table and there is a cat on the refrigerator, whereas there is a mouse on the table and the mouse wants to go and eat the cheese" (see Appendix A).

The 15 TD children from the control group approached the task with different styles; some of them correctly described the essential characteristics of each picture, others went into picking up any minimal figurative detail, and a few other children provided elaborate invented stories, logically derived from the picture. In particular, these children did so by providing intentions to some of the agents in the picture. This explains the extremely high value of the standard deviation in the number of uttered words $(\mathrm{SD}=349.6$; see Table 3$)$. 
Table 3. Qualitative analysis of the morpho-syntactic production elicited by PFLI and statistical comparisons between the three deaf children and TD children. Raw scores, $z$-scores and $p$-values of the lexical diversity, number of sentences, MLU, and morphological errors are provided.

\begin{tabular}{|c|c|c|c|c|c|}
\hline & & Case 1 & Case 2 & Case 3 & $\begin{array}{l}\text { TD Children } \\
\quad(n=15)\end{array}$ \\
\hline PFLI* & & $\begin{array}{c}\text { Raw Score } \\
\text { ( } z \text {-Score; } p \text {-Value) }\end{array}$ & $\begin{array}{c}\text { Raw Score } \\
\text { (z-Score; } p \text {-Value) }\end{array}$ & $\begin{array}{c}\text { Raw Score } \\
\text { (z-Score; } p \text {-Value) }\end{array}$ & Raw Score (SD) \\
\hline Lexical diversity & & $\begin{array}{c}370 \\
(-1.29 ; 0.09)\end{array}$ & $\begin{array}{c}262 \\
(-1.60 ; 0.05)\end{array}$ & $\begin{array}{c}828 \\
(0.01 ; 0.49)\end{array}$ & $824.2(349.6)$ \\
\hline Number of sentences & & $\begin{array}{c}122 \\
(0.57 ; 0.28)\end{array}$ & $\begin{array}{c}85 \\
(-0.027 ; 0.46)\end{array}$ & $\begin{array}{c}95 \\
(0.04 ; 0.48)\end{array}$ & $97(43.2)$ \\
\hline MLU & & $\begin{array}{l}3.03(\mathrm{SD}=1.6) \\
(-3.20 ;<0.001)\end{array}$ & $\begin{array}{l}3.08(\mathrm{SD}=2.1) \\
(-3.17 ;<\mathbf{0 . 0 0 1})\end{array}$ & $\begin{array}{l}8.7(\mathrm{SD}=6.6) \\
(-0.05 ; 0.48)\end{array}$ & $8.8(1.8)$ \\
\hline \multirow[t]{3}{*}{ Morphological errors } & & $\begin{array}{c}48 \\
(15.3 ;<0.001)\end{array}$ & $\begin{array}{c}47 \\
(15.03 ;<\mathbf{0 . 0 0 1})\end{array}$ & $\begin{array}{c}5 \\
(0.55 ; 0.48)\end{array}$ & $3.4(2.9)$ \\
\hline & Free & 32 & 35 & 1 & $1.9(2.5)$ \\
\hline & Bound & 16 & 12 & 4 & $1.5(1.5)$ \\
\hline
\end{tabular}

* Tests for the phonological evaluation of infantile speech (PFLI) [36]. PFLI was used for eliciting narrative language. Significant results are in bold.

Inspection of the narrative language elicited by the PFLI showed that the discrepancy in lexical production among the three deaf children was remarkable, and that a comparison with the control group's performance further highlighted these discrepancies. A quantitative analysis indicated a significant difference in the lexical diversity between Case 2 and the control group, while there was no difference between Case 1 and Case 3 and the control group (Table 3). However, whereas Case 1 produced a total of 370 words, Case 3 produced 828 words in describing the same pictures (Table 3 ).

The number of sentences produced by the three deaf children did not differ from the control group for any of the three deaf children (see Table 3). Instead, the MLU statistically differed between two of the deaf children (Case 1 and Case 2) and the control group, but not between the third child (Case 3) and the TD children (see Table 3).

The lower MLU scores observed in the Case 1 and 2 did not seem just characterized by a reduced number of words per sentence, but also by an abnormal organization of bound morphology. In this linguistic domain, Case 1 and Case 2 made 16 and 12 errors, respectively, whereas Case 3 made four mistakes (Table 3).

Similar conditions were observed with the use of free morphemes; again, Case 1 and Case 2 omitted determiners and prepositions 32 and 35 times, respectively, whilst Case 3 scored just one omission (Table 3). In order to get a representation of these interindividual differences, a comparative description of the picture 15 (see Appendix A) is here reported. Case 1 said, "The girl plays the [plural feminine article] dices [masculine plural noun]" thus violating gender agreement, in addition to missing the preposition "with" and turning the argument structure from an indirect to a direct one. Case 2 said "The girl ball ... dice ... the ball ... the table the chair ... sat down the girl go [for goes] the child teddy bear". Case 3 's description was strikingly different: "There was a girl named Carlotta. She was at the kindergarten and was put to seat. She casts the dice: one is green and the other one is blue ... and there is a child named Francesco and he has a teddy bear in his hand and he's glancing at the wall".

\section{Discussion}

Our study investigated three prelingually deaf children who were implanted by 6 years of age and achieved strongly discrepant levels of grammatical skills, despite their similar family and clinical histories, hearing loss levels, postimplant hearing threshold, and nonverbal intelligence levels. One major difference concerned their age at CI implantation, since Case 3 was implanted at 5.9 years of age, while the other two children were implanted at 2.7 and 3.7 years of age. Surprisingly, however, the late-implanted child acquired 
language skills comparable to those of TD children, whereas the other two children (Cases 1 and 2) showed severe morpho-syntactic deficits, in both comprehension and production.

In the literature, some studies reported that improvement in auditory perception provided by $\mathrm{CI}$ has a strong impact on language acquisition of children with hearing loss (e.g., [2-5]). An early age of implantation, in fact, fosters the recruitment of a vast neuronal network, thus expanding the opportunities for setting up an efficient neural architecture for the acquisition of language. This line of reasoning is supported by measures of P1 latencies, which vary as a function of chronological age and, therefore, provide a measure of the central auditory pathway maturation. A study by Sharma et al. [39] showed that "children with CI who had the longest period of auditory deprivation before implantation demonstrated abnormally long cortical response latencies to speech stimuli. On the contrary, those children who had the shortest period of auditory deprivation (3.5 years or less) demonstrated age-appropriate latency responses" (p. 511). A subsequent study by Sharma et al. [40] further documented that the development of P1 latencies in two congenitally deaf children, who were implanted at 13 and 14 months of age, followed a normal trend. In particular, the authors examined the relationship between P1 latencies and the development of canonical babbling; the findings revealed that the development of P1 response latencies and the development of early communicative behavior followed a similar trajectory. The authors aptly observed that these early stages of speech development in early implanted children "may be positively influenced by the rate of plastic changes in central auditory pathways" [40] (p. 511). In other words, early cochlear implantation appears to be optimal for the development of neural correlates of auditory perception because it allows the children to exploit the development of neuronal connections in the brain.

Yet, as many studies observed (e.g., [6-11]), early cochlear implantation does not necessarily correspond to age-appropriate language skills. As reported by Marschark and colleagues [41], it is important to remain aware that CI may not be sufficient to overcome the risk of weaknesses in several aspects of language. Other factors, such as age at first amplification, type of speech therapy, early sign language exposure, maternal educational level, and language input, appear to strongly influence the language development of these children [1]. It should be noted that Cases 1 and 2, relative to Case 3, received the first amplification and therapy a few months later; this condition may have negatively influenced their language acquisition. By contrast, the mothers of the Case 1 and 2 showed higher educational levels than the mother of the Case 3. It is widely documented that the maternal educational level plays an important role in child language acquisition in deaf children with CI [42]. Thus, we can exclude that the linguistic discrepancies between Cases 1-2 and Case 3 are attributable to maternal educational level. There is also recent research that shows that deaf children of hearing parents demonstrate age-level verbal vocabulary growth when exposed to American Sign Language (ASL) by 6 months of age [43]; the lack of access to sign language that characterized the children of the present study may has been a further negative factor for their language development. However, it is important to note that this negative condition affected all three children and not just the first two cases. Thus, taking into account all these conditions and the fact that Cases 1 and 2 showed severely impaired morpho-syntactic abilities, whereas the Case 3 showed age-appropriate skills, it is not unreasonable to put forward the hypothesis that the morpho-syntactic deficit that characterized Cases 1 and 2 may reflect not only the lack of exposure to a natural and optimal hearing during the critical perceptual window, but also some concomitant specific impairment to the language system.

In support of this hypothesis is the qualitatively fine-grained analysis of the language disorders that characterized this single-case investigation and that allowed highlighting atypical morpho-syntactical errors in Cases 1 and 2 quite similar to those made by children with DLD. A glance at the number of errors in the syntactic comprehension task (TCGB) indicates that both more sophisticated and less sophisticated syntactic structures were not properly mastered by both Case 1 and Case 2 (with a mean error of 12.5 and 24.5, 
respectively), whereas Case 3 had a mean error of 1.5 (well within the normal range). Since the discrepancies between Cases 1-2 and Case 3 cut across the entire set of syntactic structures investigated by the TCGB except one (Case 3 only had one abnormal error rate on passive affirmative sentences, compared to the normative range), it appears that the grammatical errors made by the first two deaf children may reflect an extended impairment to the morpho-syntactic system. Furthermore, the profile of the syntactic errors appeared not to be typical of a younger age. Case 1 and Case 2, for instance, proved to be unable in manipulating the sentences requiring discrimination of flexional morphology; this linguistic competence is clearly within reach of much younger children without difficulty [35]. Our findings are in line with other studies on case reports [28,29,44], thus providing new evidence for the fact that, in certain circumstances, the language acquisition of deaf children with CI may follow profoundly divergent patterns. Our data suggest that, in some cases, we may not be facing a simple morpho-syntactic delay due to perceptual difficulties or to the duration of hearing exposure, but a disorder of the processes of language acquisition.

Inspection of the spontaneous language showed that the discrepancy in morphosyntactic production among the three deaf children was remarkable and that a comparison with the control group's performance further highlighted these discrepancies. Furthermore, the qualitative analysis of the spontaneous productions showed, in Cases 1 and 2 , atypical morpho-syntactic errors, not only attributable to deafness. As can be seen from the transcripts (see Appendix A), the morpho-syntactic errors of these two children appeared very similar to those observed in Italian normal-hearing children with DLD. In fact, in these two children, it was possible to observe omissions of nouns and verbs, article and prepositions substitutions, atypical verb conjugations, and extremely simple (even telegraphic) sentences, which are all markers of DLD (e.g., [30,31,45]). A small MLU also appears to be an important marker of DLD [46]. Most children with DLD show a language production, measured as MLU, significantly below the age level $[47,48]$. Hammer and colleagues [49] found that the $75 \%$ of the children with DLD scored below age expectations on MLU as opposed to $35.4 \%$ in the group of children with CI. Moreover, most of the children with CI achieved appropriate competencies on finite verb production, whereas children with DLD did not. Our findings appear in line with these data on children with DLD; in effect, the MLU was severely impaired in Case 1 and Case 2. These two children reached an MLU of 3.03 and 3.08, respectively, whereas Case 3 and TD children showed an MLU of 8.7 and 8.8, respectively. A more systematic collection of data is clearly required; however, we tentatively suggest that a concomitant occurrence of deafness and morphosyntactic impairment may explain a proportion of variability in linguistic proficiency of some implanted children.

Children with DLD show that normal hearing per se is not a sufficient condition for language to be acquired at normal rate [50]. There were also studies that found DLD in signing deaf children, supporting the theoretical argument that DLD can be evident regardless of the modality of communication and can affect deaf children [51,52]. For instance, Herman and colleagues [51] looked at narratives in British Sign Language (BSL) and showed that the DLD-diagnosed deaf children performed poorly on verb morphology, and their narratives exhibited less structure and were shorter than those of the TD children. Marshall and colleagues [52] found deaf children with DLD less able to accurately repeat all elements of BSL sentences, including grammatical constructions. These findings seem to indicate that atypicalities in the sign modality show many of the same characteristics as linguistic deficits in hearing children [53].

Our findings appear in line with these data and seem, therefore, to provide new evidence to the hypothesis that other single-case studies have suggested $[28,29,44]$, i.e., that the deafness can, in some cases, be associated with a DLD, as it would seem for Cases 1 and 2. In contrast, the good morpho-syntactic performances observed in Case 3 may be the result of both the earlier amplification and therapy relative to other two children with $\mathrm{CI}$ and, in line with our hypothesis, language area integrity. 
Limitations of this work should be acknowledged. First, being a single-case study, the generalizability of our findings should be carefully considered. Replication of the present findings with larger samples is clearly needed in the future. In particular, it appears necessary to conduct a detailed qualitative analysis of the language skills in a larger group of deaf children with an earlier age at CI surgery and comparing them with groups of hearing children with DLD and signing deaf children with DLD. Second, the present work did not consider the role of domain-general neurocognitive processes, such as sequential processing, working memory, and executive functions, which several authors found to strongly influence the syntactic abilities of children with DLD [54-56], as well as the linguistic outcomes of deaf children with CI [18-20]. Third, although we controlled for maternal educational level, we did not investigate other important environmental factors, such as level of parental IQ, maternal language input, and family psychological wellbeing, which several studies have shown to be related to language and learning acquisition in this and other clinical populations $[42,57,58]$. Future research should move in these directions. Lastly, a further limitation of this study is the absence of neurofunctional correlates, which are crucial if we aim to explain the association between deafness and language system functional deficit. Despite these limitations, the results of this single-case investigation appear sufficient to suggest this association.

\section{Conclusions}

Numerous variables, such as age at first amplification and at beginning language rehabilitation, early sign language exposure, age at implantation, cognitive skills, and maternal education level and language input, may influence the linguistic outcomes of deaf children with CI; as previously reported in this work, these variables have been extensively studied in this clinical population. Instead, few are the studies that investigated if the reported delay in language acquisition among implanted children may be characterized as a domain-specific language disorder. Cases 1 and 2 showed grammar impairments very similar to those of children with DLD. Thus, the profound morpho-syntactic deficits observed in these two cases may be the result of more co-occurring factors: deafness-related factors, such as the lack of full access to a complete language (verbal and sign language) during the critical perceptual window $[1,21,22]$, as well as the presence of a concomitant DLD $[28,29,44]$.

In other words, we are suggesting that the persistent language impairment in some deaf children with CI may be the final outcome of a pre-existing impairment of the language system, combined with the negative effects of a profound congenital deafness. Early identification of domain-specific language impairments in these children may allow for planning and implementation of individualized interventions. To this end, a qualitative and accurate analysis of the type of morpho-syntactic errors appears needed during the language assessment of these children. Furthermore, interventions are needed that specifically act on affected language domains, similarly to that done for children with DLD [59].

Author Contributions: Conceptualization, E.B., S.B., M.T.B. and G.C.; data curation, E.B. and S.B.; formal analysis, S.B.; funding acquisition, M.S.; methodology, E.B., S.B., M.T.B. and G.C.; supervision, G.C.; writing-original draft, E.B., S.B. and G.C.; writing-review and editing, M.C. and M.S. All authors have read and agreed to the published version of the manuscript.

Funding: This research did not receive any specific grant from funding agencies in the public, commercial, or not-for-profit sectors.

Institutional Review Board Statement: Since an Ethics Commission was not present in the University of Parma where and when the study was conducted, the study did not receive formal ethical approval.

Informed Consent Statement: Informed consent was obtained from all subjects involved in the study.

Data Availability Statement: The data presented in this study are available on request from the corresponding author. 
Acknowledgments: The authors are very grateful to the families and children who participated in this study. We also thank the school "Italo Calvino" of Calerno (Reggio Emilia, Italy) that allowed the data collection in TD children.

Conflicts of Interest: The authors declare no conflict of interest.

\section{Appendix A}

For the purposes of our study, 10 pictures (i.e., no. 5, 10, 13, 15, 24, 28, 29, 31, 39, and 48) were selected from the tests for the phonological evaluation of infant speech (PFLI) [36].

Picture 5 [A child watching a mouse that is running toward the cheese; a cat is also watching the mouse and it seems to be readily hunting the mouse].

Case 1

"vedere il topo"

"to watch the mouse"

Case 2

"il bambino guarda il topo ... il formaggio"

"the child watches the mouse ... the cheese"

"il topo mangio gatto"

"the mouse eat cat"

"mangia il ... la formaggio"

"[he] eats the [masc. article] ... the [fem. article] cheese [masc. noun]"

Case 3

"c'era un bambino che si chiamava Luca/lui sul tavolo ha messo un formaggio e sopra il frigorifero c'é un gatto e invece sulla tavola c'è un topo/e il topo vuole andare a mangiare il formaggio"

"there was a child named Luca/he put a cheese on the table and there is a cat on the refrigerator and on the contrary there is a mouse on the table/and the mouse want to go to eat the cheese"

Picture 10 [The old man wants to repair a tap because of overflowing water].

Case 1

"bagnato tutto per terra"

"wetted all on the ground"

"il nonno [ag] giusta ... dopo chiude l'acqua"

"the grandfather $[\mathrm{r}]$ eparis ... after turns off the water"

"il nonno [é] bagnato per l'acqua"

"the grandfather [is] wetted for the water"

Case 2

"il nonno aggiusta ... perché rotto lavandino" [il nonno aggiusta il lavandino perchè è rotto]

"the grandfather repairs ... because broken tap [the grandfather repairs the tap because is broken]

"per terra [c'é] [dell'] acqua"

"on the ground [there is] [the] water"

Case 3

"c'era un signore che si chiamava Giuseppe e andò in bagno/e i tubi erano tutti rotti e usciva tutta l'acqua e lui prende una chiave inglese per buttare il tubo così non esce l'acqua"

"there was a man named Giuseppe end he went to the bathroom/and the tubes were broken and the water overflowed and he takes a tool for to throw the tube so the water doesn't overflow"

Picture 13 [The girl is sleeping in the bed, there is a clock on the ground, and there is a doll on the carpet].

Case 1

"la bambina dorme sul letto dentro [la] coperta"

"the girl sleeps on the bed within [the] blanket" 
"l'orologio ... la bambola sopra [il] [pavi] mento"

"the clock ... the doll on [the] [f] loor"

"la bambina andiamo a scuola"

"the girl [we] go to school"

"mette [lo] zaino"

"[she] wears [the] knapsack"

Case 2

"la bambina dorme sul letto ... [la] bambola dorme su per terra tappeto"

"the girl sleeps on the bed ... [the] doll sleeps on the ground [on the] carpet"

"la bambina vado a scuola"

"the girl go to school"

Case 3

"una bambina si chiama Giulia/Giulia é a letto che dorme e in terra c'é una sveglia poi c'é un tappeto e poi c'é una bambola"

"a girl is named Giulia/Giulia is sleeping on the bed and there is a clock on the ground then there is a carpet and then there is a doll"

Picture 15 [There are some games in the room; a child gives dice to the girl who is seated and playing with the dice; another child has a teddy bear in his hand].

Case 1

"La bambina gioca le dadi"

"the girl plays the [fem. Article] dice [masc. noun]

"porta mano con l'orsetto"

"[he] brings hand with the teddy bear"

"giochi sul pavamento"

"games on the floor"

Case 2

"la bambina palla/cubi/la palla/il tavolo la sedia/seduta la bambina"

"the girl ball/dice/the ball/the table/the chair/sat down the girl"

"vanno il bambino [con] [1'] orsetto"

"[they] go the child [with] [the] teddy bear"

"il bambino vanno orsetto"

"the child [they] go teddy bear"

Case 3

“c'era una bambina che si chiamava Carlotta/lei era all'asilo che si metteva a sedere/e lei 13ancia due dadi: uno verde e uno blu e c'é un bambino che si chiama Francesco e ha un orsetto nella mano e guarda il muro"

"there was a girl named Carlotta/she was at the kindergarten and was put to seat/she casts the dice: one is green and the other is blue/and there is a child named Francesco and he has a teddy bear in his hand and he's glancing at the wall"

Picture 24 [A child is skiing, and a girl is sledging].

Case 1

"siamo in alberi"

"[we] are in trees"

"seduto nel neve"

"sat in the [masc. prep.] snow [fem. noun]"

"tutto neve"

"all snow"

Case 2

"I bambini giocano su [lla] neve"

"the children play with [the] snow"

"il bambino ascia sci/tuta [da] sci/tutto sci"

"the child [unknown word] skies/suit [for] ski/all skies"

Case 3 
"Alessandro va in montagna con la sua bimba e va a sciare in montagna/poi c'é un'altra bimba che si chiama Veronica e ha le trecce che ha uno slittino e scia"

"Alessandro goes in mountain with his child and he goes to ski in mountain/then there is another girl named Veronica and she have the plaits and a sledge and she skies"

Picture 28 [A girl is on the beach; she is seated on the sand and she has a shovel in her hand. On the sea, there are three boats].

Case 1

"ce ne é tre"

"there is [are] three"

"la bambina [é] seduto"

"the girl [is] seated [masculine]

Case 2

"la bambina giocano in sabbia"

"the girl play [third pers. plur.] in [on the] sand"

"e poi la bambina sabbia"

"and then the girl sand"

Case 3

"c'era una volta una bambina che si chiamava Irene/Irene che andò al mare e si mette sulla spiaggia/e aveva una paletta verde in mano/e nel mare c'erano tre barche: due rosse e una verde"

"once upon a time a girl named Irene/Irene that went to the sea and she put on the sand/and she had a green shovel in her hand/and there are three boats on the sea: two red and another green"

Picture 29 [There is a zebra in the cage; the child wants to caress the elephant].

Case 1

"il bambino saluta [l'] elefante ... [lo] [ac] carezza"

"the child salutes [the] elephant ... pets [it]"

"nella sabbia" (nella gabbia)

"in the sand [cage]

Case 2

"I bambino guardare [1'] elefante"

"the [plur. article] child to watch elephant"

Case 3

"c'é un bambino che si chiama Giancarlo e vuole toccare la proboscide di un elefante grosso/e poi c'é una zebra piccola bianca e nera"

"there is a child named Giancarlo and he want to touch the trunk of a big elephant/and then there is a little black and white zebra"

Picture 31 [The girl is eating candies, while the child is eating an ice cream].

Case 1

"sul tavolo [sono] tante le caramelle"

"on the table many candies"

"la bambina [è] seduta [sul] la sedia"

"the girl [is] sat [on] the chair"

"il bambino lecca [il] gelato nel lingua"

"the child licks ice-cream in the tongue"

"le caramelle ai bambine"

"the candies at the [masc. prep.] girls [fem. noun]"

Case 2

"il bambino mangia la caramelle"

"the child eats the candies"

Case 3

"c'era una bambina che si chiamava Eleonora e si mette sul tavolo/ha le trecce é bionda e sul tavolo ha delle caramelle e dei cioccolatini/lei mangia una cioccolatina e suo fratello mangia un bel gelato con la lingua" 
"there was a girl named Eleonora and she was on the table/she has the plaits, the blonde hairs and she has some candies and chocolates on the table/she eats a chocolate and her brother eats a good ice-cream with his tongue"

Picture 39 [A girl is holding a chick in her hand, and she is feeding some grains to other chicks and hens].

Case 1

"I chicchi lì ... le galline"

"the grains there ... the hens"

"un pulcini"

"the [sing. article] chicks [plur. noun]"

"anitra sopra nell'acqua"

"duck on the water"

Case 2

"la bambina lanciano"

"the girl hurl [third pers. plur.]"

"su una mano [il] pulcino"

"on one hand [the] chick"

Case 3

"c'era una bambina che si chiamava Erika/e dava da mangiare [a] galline e pulcini"

"there was a girl named Erika/and she gave to eat [at] hens and chicks"

Picture 48 [There are some games and a girl is jumping a rope].

Case 1

"poi [i] piedi ... in piedi prende sotto [le] scarpe"

"then [the] foot ... in foot takes under [the] shoes"

Case 2

"la bambina saltano la corda"

"the girl jump [third pers. plur.] the rope"

"poi le mani lanciano la bambina"

"then the hands hurl the girl"

Case 3

"c'era una bambina che si chiamava Teresa/e giocava e c'era una bicicletta piccola/una trottola grande/e Teresa gioca con la corda e fa i salti"

"there was a girl named Teresa/and she played and there was a little bike/a big spinning/and Teresa plays with the rope and she make the jumps"

\section{References}

1. Rinaldi, P.; Pavani, F.; Caselli, M.C. Developmental, cognitive, and neurocognitive perspectives on language development in children who use cochlear implants. In Handbook of Deaf Studies in Learning and Cognition; Knoors, H., Marschark, M., Eds.; Oxford University Press: Oxford, UK, 2020; pp. 33-45. [CrossRef]

2. Svirsky, M.A.; Robbins, A.M.; Kirk, K.I.; Pisoni, D.B.; Miyamoto, R.T. Language development in profoundly deaf children with cochlear implants. Psychol. Sci. 2000, 11, 153-158. [CrossRef]

3. Cuda, D.; Murri, A.; Guerzoni, L.; Fabrizi, E.; Mariani, V. Pre-school children have better spoken language when early implanted. Int. J. Pediatr. Otorhi. 2014, 78, 1327-1331. [CrossRef] [PubMed]

4. Kral, A.; Sharma, A. Developmental neuroplasticity after cochlear implantation. Trends Neurosci. 2012, 35, 111-122. [CrossRef] [PubMed]

5. Robbins, A.M.; Koch, D.B.; Osberger, M.J.; Zimmerman-Philips, S.; Kishon-Rabin, L. Effect of age at cochlear implantation on auditory skill development in infants and toddlers. Arch. Otolaryngol. Head Neck Surg. 2004, 130, 570-574. [CrossRef]

6. Geers, A.E. Speech language, and reading skills after early cochlear implantation. Arch. Otolaryngol. Head Neck Surg. 2004, 130, 634-638. [CrossRef]

7. Nikolopoulos, T.P.; Dyar, D.; Archbold, S.; O’Donoghue, G.M. Development of spoken language grammar following cochlear implantation in prelingually deaf children. Arch. Otolaryngol. Head Neck Surg. 2004, 130, 629-633. [CrossRef]

8. Lund, E. Vocabulary knowledge of children with cochlear implants: A meta-analysis. J. Deaf. Stud. Deaf. Educ. 2016, 21, 107-121. [CrossRef]

9. Rinaldi, R.; Baruffaldi, F.; Burdo, S.; Caselli, M.C. Linguistic and pragmatic skills in toddlers with cochlear implant. Int. J. Lang. Comm. Dis. 2013, 48, 715-725. [CrossRef] [PubMed] 
10. Soleymani, Z.; Mahmoodabadi, N.; Nouri, M.M. Language skills and phonological awareness in children with cochlear implants and normal hearing. Int. J. Pediatr. Otorhi. 2016, 83, 16-21. [CrossRef]

11. Wie, O.B. Language development in children after receiving bilateral cochlear implants between 5 and 18 months. Int. J. Pediatr. Otorhi. 2010, 74, 1258-1266. [CrossRef]

12. Geers, A.E.; Mitchell, C.M.; Warner-Czyz, A.; Wang, N.Y.; Eisenberg, L.S.; CDaCI Investigative Team. Early sign language exposure and cochlear implantation benefits. Pediatrics 2017, 140, e20163489. [CrossRef]

13. Van Wieringen, A.; Wouters, J. What can we expect of normally-developing children implanted at a young age with respect to their auditory, linguistic and cognitive skills? Hear. Res. 2015, 322, 171-179. [CrossRef]

14. Pisoni, D.B.; Kronenberger, W.G.; Harris, M.S.; Moberly, A.C. Three challenges for future research on cochlear implants. World J. Otorhinolaryng-Head Neck Surg. 2017, 3, 240-254. [CrossRef]

15. Jiménez, M.S.; Pino, M.J.; Herruzo, J. A comparative study of speech development between deaf children with cochlear implants who have been educated with spoken or spoken+ sign language. Int. J. Ped. Otorhinolaryng 2009, 73, 109-114. [CrossRef]

16. Rinaldi, P.; Caselli, M.C. Language development in a bimodal bilingual child with cochlear implant: A longitudinal study. Bilingual 2014, 17, 798. [CrossRef]

17. Szagun, G.; Schramm, S.A. Sources of variability in language development of children with cochlear implants: Age at implantation, parental language, and early features of children's language construction. J. Child. Lan. 2016, 43, 505-536. [CrossRef]

18. Conway, C.M.; Pisoni, D.B.; Anaya, E.M.; Karpicke, J.; Henning, S.C. Implicit sequence learning in deaf children with cochlear implants. Dev. Sci. 2011, 14, 69-82. [CrossRef] [PubMed]

19. Kronenberger, W.G.; Pisoni, D.B.; Harris, M.S.; Hoen, H.M.; Xu, H.; Miyamoto, R.T. Profiles of verbal working memory growth predict speech and language development in children with cochlear implants. J. Speech Lang. Hear. Res. 2013, 56, 805-825. [CrossRef]

20. Pisoni, D.; Kronenberger, W.; Roman, A.; Geers, A. Measures of digit span and verbal rehearsal speed in deaf children following more than 10 years of cochlear implantation. Ear Hear. 2011, 32, 60S-74S. [CrossRef] [PubMed]

21. Mayberry, R.I.; Kluender, R. Rethinking the critical period for language: New insights into an old question from American Sign Language. Biling. Lang. Cogn. 2018, 21, 886-905. [CrossRef]

22. Werker, J.F.; Tees, R.C. Speech perception as a window for understanding plasticity and commitment in language systems of the brain. Dev. Psychob. 2005, 46, 233-251. [CrossRef]

23. Caselli, M.C.; Rinaldi, P.; Onofrio, D.; Tomasuolo, E. Language skills and literacy of deaf children in the era of cochlear implantation: Suggestions for teaching through e-learning visual environments. In Educating Deaf Learners; Knoors, H., Marschark, M., Eds.; Oxford University Press: Oxford, UK, 2015; pp. 443-460.

24. Majorano, M.; Guidotti, L.; Guerzoni, L.; Murri, A.; Morelli, M.; Cuda, D.; Lavelli, M. Spontaneous language production of Italian children with cochlear implants and their mothers in two interactive contexts. Int. J. Lang. Comm. Dis. 2018, 53, 70-84. [CrossRef]

25. Caselli, M.C.; Rinaldi, P.; Varuzza, C.; Giuliani, A.; Burdo, S. Cochlear implant in the second year of life: Lexical and grammatical outcomes. J. Speech Lang. Hear. Res. 2012, 55, 382-394. [CrossRef]

26. Chilosi, A.M.; Comparini, A.; Scusa, M.F.; Orazini, L.; Forli, F.; Cipriani, P.; Berrettini, S. A longitudinal study of lexical and grammar development in deaf Italian children provided with early cochlear implantation. Ear Hear. 2013, 34, e28-e37. [CrossRef]

27. Giustolisi, B.; Guasti, M.T.; Nicastri, M.; Mancini, P.; Palma, S.; Genovese, E.; Arosio, F. Production of third-person direct object clitics in children with cochlear implants speaking Italian. Clin. Linguist. Phonet. 2021, 35, 577-591. [CrossRef] [PubMed]

28. De Stefano, P.; Pisani, F.; Cossu, G. Diverse Linguistic Development in Prelingually Deaf Children with Cochlear Implants. Behav. Neurol. 2019, 2019, 1630718. [CrossRef]

29. Hawker, K.; Ramirez-Inscoe, J.; Bishop, D.V.; Twomey, T.; O’Donoghue, G.M.; Moore, D.R. Disproportionate language impairment in children using cochlear implants. Ear Hear. 2008, 29, 467-471. [CrossRef]

30. Bortolini, U.; Caselli, M.C.; Deevy, P.; Leonard, L. Specific language impairment in Italian: The first steps in the search for a clinical marker. Int. J. Lang. Comm. Dis. 2020, 37, 77-93. [CrossRef]

31. Chilosi, A.M.; Cipriani, P. Il Bambino Disfasico; Del Cerro: Tirrenia (PI), Italy, 1991.

32. Amigoni, E.; Barbot, A.; Bossi, R.; Cornacchia, L.; De Filippis, A.; Cippone, P.; Leotta, M.G. PCVRAR. Protocollo Comune di Valutazione dei Risultati in Audiologia Riabilitativa; C.R.O.: Firenze, Italy, 1997.

33. Geers, A.E.; Moog, J. Effectiveness of cochlear implants and tactile aids for deaf children: The sensory of the Central Institute for the Deaf. Volta Rev. 1994, 96, 232-235.

34. Raven, J.C. Coloured Progressive Matrices (CPM); Organizzazioni Speciali: Firenze, Italy, 1984.

35. Chilosi, A.M.; Cipriani, P. TCGB - Test. di Comprensione Grammaticale per Bambini [Test. of Grammatical Comprehension for Children]; Del Cerro: Firenze, Italy, 1995.

36. Bortolini, U. Pfli. Prove per la Valutazione Fonologica del Linguaggio Infantile; Edizioni Del Cerro: Pisa, Italy, 1995.

37. Owens, R.E. Language Disorders. A Functional Approach to Assessment and Intervention; Allyn \& Bacon: Boston, MA, USA, 1995.

38. Lena, L.; Pinton, A.; Trombetti, B. Valutare Linguaggio e Comunicazione; Carocci: Roma, Italy, 2004.

39. Sharma, A.; Dorman, M.F.; Sphar, A.J. Rapid development of cortical auditory evoked potentials after early cochlear implantation. NeuroReport 2002, 13, 1365-1368. [CrossRef] [PubMed]

40. Sharma, A.; Tobey, E.; Dorman, M.F.; Bharadawaj, S.; Martin, K.; Gilley, P.; Kunkel, F. Central auditory maturation and babbling development in infants with cochlear implant. Arch. Otolaryngol. Head Neck Surg. 2004, 130, 511-516. [CrossRef] [PubMed] 
41. Marschark, M.; Duchesne, L.; Pisoni, D. Effects of Age at Cochlear Implantation on Learning and Cognition: A Critical Assessment. Am. J. Speech-Lang. Pat. 2019, 28, 1318-1334. [CrossRef]

42. Crowe, K.; McLeod, S. A systematic review of cross-linguistic and multilingual speech and language outcomes for children with hearing loss. Int. J. Biling. Educ. Biling. 2014, 17, 287-309. [CrossRef]

43. Caselli, N.; Pyers, J.; Lieberman, A.M. Deaf children of hearing parents have age-level vocabulary growth when exposed to American Sign Language by 6 months of age. J. Ped. 2021, 232, 229-236. [CrossRef]

44. Boria, S.; Mastroprimiano, E.; Benassi, E.; Berghenti, M.T. Traiettorie linguistiche divergenti nel bambino con impianto cocleare. Analisi longitudinale di due casi con disturbo della morfosintassi. Logop. Comun. 2018, 14, 185-202. [CrossRef]

45. Marini, A.; Fabbro, F.; Tavano, A. Assessment of linguistic abilities in Italian children with Specific Language Impairment. Neuropsych 2008, 46, 2816-2823. [CrossRef]

46. Andreou, G.; Lemoni, G. Narrative Skills of Monolingual and Bilingual Pre-School and Primary School Children with Developmental Language Disorder (DLD): A Systematic Review. Open J. Mod. Ling. 2020, 10, 429-458. [CrossRef]

47. Bortolini, U.; Leonard, L.B. Phonology and children with specific language impairment: Status of structural constraints in two languages. J. Commun. Disord. 2020, 33, 131-150. [CrossRef]

48. Rice, M.L.; Redmond, S.M.; Hoffman, L. Mean length of utterance in children with Specific Language Impairment and in younger control children shows concurrent validity and stable and parallel growth trajectories. J. Speech Hear. Res. 2006, 49, 793-808. [CrossRef]

49. Hammer, A.; Coene, M.; Rooryck, J.; Govaerts, P.J. The production of Dutch finite verb morphology: A comparison between hearing-impaired CI children and specific language impaired children. Lingua 2014, 139, 68-79. [CrossRef]

50. Leonard, L.B. Children with Specific Language Impairment; MIT Press: Cambridge, MA, USA, 1998.

51. Herman, R.; Rowley, K.; Mason, K.; Morgan, G. Deficits in narrative abilities in child British Sign Language users with specific language impairment. Int. J. Lang. Comm. Dis. 2014, 49, 343-353. [CrossRef] [PubMed]

52. Marshall, C.R.; Mason, K.; Rowley, K.; Herman, R.; Atkinson, J.; Woll, B.; Morgan, G. Sentence repetition in deaf chil- dren with specific language impairment in British Sign Language. Lang. Lear. Dev. 2015, 11, 237-251. [CrossRef]

53. Quinto-Pozos, D.; Singleton, J.L.; Hauser, P.C. A case of specific language impairment in a deaf signer of American Sign Language. J. Deaf Stud. Deaf Educ. 2017, 22, 204-218. [CrossRef]

54. Leonard, L.B.; Deevy, P.; Fey, M.; Bredin-oja, S. Sentence comprehension in specific language impairment: A task designed to distinguish between cognitive capacity and syntactic complexity. J. Speech. Hear. Res. 2013, 56, 577-589. [CrossRef]

55. Pettenati, P.; Benassi, E.; Deevy, P.; Leonard, L.B.; Caselli, M.C. Extra-linguistic influences on sentence comprehension in Italianspeaking children with and without specific language impairment. Int. J. Lang. Comm. Dis. 2015, 50, 312-321. [CrossRef] [PubMed]

56. Veraksa, A.; Bukhalenkova, D.; Kartushina, N.; Oshchepkova, E. The Relationship between Executive Functions and Language Production in 5-6-Year-Old Children: Insights from Working Memory and Storytelling. Beh. Sci. 2020, 10, 52. [CrossRef]

57. Benassi, E.; Guarini, A.; Savini, S.; Iverson, J.M.; Caselli, M.C.; Alessandroni, R.; Faldella, G.; Sansavini, A. Maternal responses and development of communication skills in extremely preterm infants. First Lang. 2018, 38, 175-197. [CrossRef]

58. Scorza, M.; Benassi, E.; Gennaro, A.; Bruganelli, C.; Stella, G. Psychopathological symptoms in Italian children and adolescents with Specific Learning Disorder: What do mothers and fathers report about? BPA Appl. Psychol. Bull. 2018, 66, 281.

59. Rinaldi, S.; Caselli, M.C.; Cofelice, V.; D'Amico, S.; De Cagno, A.G.; Della Corte, G.; Zoccolotti, P. Efficacy of the Treatment of Developmental Language Disorder: A Systematic Review. Brain Sc. 2021, 11, 407. [CrossRef] 